\title{
Increased size of third ventricle in patients with multiple sclerosis and chronic cerebrospinal venous insufficiency
}

This article was published in the following Dove Press journal:

Journal of Vascular Diagnostics

17 September 2014

Number of times this article has been viewed

\author{
Aldo d'Alessandro' \\ Sandro Mandolesi ${ }^{2}$ \\ Tarcisio Niglio ${ }^{6}$ \\ Augusto Orsini ${ }^{3}$ \\ Pierfrancesco Di Cello ${ }^{3-5}$ \\ Fabio Pelle ${ }^{5}$ \\ Fabio Mora ${ }^{3}$ \\ Alessandro d'Alessandro ${ }^{4}$ \\ Dimitri Mandolesi ${ }^{7}$ \\ Francesco Fedele ${ }^{2}$ \\ 'Department of Angiology, \\ T Masselli-Mascia Hospital, San \\ Severo (FG), Italy; ${ }^{2}$ Department \\ of Cardio-vascular and Respiratory \\ Sciences, Nephrology and Geriatric, \\ Sapienza University, Rome, Italy; \\ ${ }^{3}$ Department of Vascular Surgery, \\ Gioia Hospital, Sora (FR), Italy; \\ ${ }^{4}$ Faculty of Medicine, Catholic \\ University "Our Lady of Good \\ Counsel”, Tirana, Albania; \\ ${ }^{5}$ Department of Surgery, Sapienza \\ University, Rome, Italy; ${ }^{6}$ Istituto \\ Superiore di Sanità, Rome, Italy; \\ ${ }^{7}$ Medicina del Lavoro, Sapienza \\ University, Rome, Italy
}

Objective: The aim of the present study was to assess the size of the third ventricle in a sample of patients with multiple sclerosis (MS) affected by chronic cerebrospinal venous insufficiency (CCSVI), versus size of the third ventricle in a healthy control group.

Background: CCSVI, a new nosological vascular pattern, has recently been associated with MS.

Methods: We enrolled 33 patients affected by MS (three in the primary progressive clinical course, 23 in the relapsing-remitting clinical course, and seven in the secondary-progressive clinical course). All patients had been affected by CCSVI and were tested using an echo color Doppler (ECD) imaging unit. The group of 33 affected by both MS and CCSVI (MS-CCSVI) was composed of 19 females and 14 males with a mean age of $40 \pm 10$ years, from a minimum age of 20 years to a maximum age of 66 years, with a median of 40 years and a mode of 32 years. We compared the 33 MS-CCSVI patients with 33 healthy control subjects of similar sex and age. In the MS-CCSVI group, the MS clinical severity was expressed by expanded disability status scale (EDSS) score: light (19 patients, scoring 1, 2, or 3); medium (ten patients with a score of 4, 5, or 6), and severe (four patients with a score of 7, 8, or 9). The average duration of the MS was $10 \pm 7$ years (from a minimum of 1 to a maximum of 26 years, with a median of 10 years and a mode of 1 year).

Results: In the MS-CCSVI group, the third ventricle diameter was $6.2 \pm 1.7 \mathrm{~mm}$ (from a minimum of $2.5 \mathrm{~mm}$ to a maximum of $9.2 \mathrm{~mm}$, with a median of $6.3 \mathrm{~mm}$, and a mode of $6.0 \mathrm{~mm}$ ). Our data showed that 29 patients $(88 \%$ ) had an increase in third ventricle diameter, whereas only four patients $(12 \%)$ had physiological size (less than $4 \mathrm{~mm}$ ) comparable to all healthy control group subjects $(27.28 \%)$. These results show that the increase in the third ventricle diameter could represent a criterion of positivity of neurological disease in patients with CCSVI.

Keywords: MS, CSSVI, increased size of the third ventricle

\section{Introduction}

Multiple sclerosis (MS), the most common neurological disorder in young adults, is traditionally considered to have autoimmune determinants. ${ }^{1}$ The multi-step mechanism of the disease involves inflammation, demyelination, and neuro-degeneration of the central nervous system. ${ }^{1-3}$ It is interesting to note that, from the time of the first histological description by Charcot, ${ }^{4} \mathrm{MS}$ plaques were known to be venocentric. ${ }^{2,4}$ Both magnetic resonance venography $(\mathrm{MRV})^{5-9}$ and postmortem studies show a central vein oriented on the long axis of the inflammatory lesion.

In addition, as usually happens in several neurodegenerative disorders, the brain and spinal cord of MS-affected patients contain abnormally high levels of redox-active
Correspondence: Aldo d'Alessandro Department of Angiology, “T. MasselliMascia" Hospital,Via Risorgimento,

7 San Severo (FG), Italy

Tel +39 3299780066

$\mathrm{Fax}+390882200431$

Email aldodalessandro@tiscali.it 
metals, particularly iron, ${ }^{10}$ documented by advanced magnetic resonance imaging $(\mathrm{MRI})^{11}$ and enhanced histochemical methods. ${ }^{12,13}$

The several forms of MS, ${ }^{1,2,14}$ are based on clinical characteristics: relapsing-remitting MS (RRMS), comprising $85 \%$ of MS patients, ${ }^{15}$ secondary-progressive MS (SPMS), comprising $15 \%$ of MS patients, ${ }^{14,15}$ and primary progressive MS (PPMS), comprising 5\% of MS patients. ${ }^{16}$ RRM is the most common form of the disease. Patients affected by this form tend to experience an attack or series of attacks (exacerbations) followed by complete or partial remission. ${ }^{15}$ SPMS begins with a relapsing-remitting (RR) course (RRMS); it is chronic and progressive. There are no real periods of remission, only breaks in attack duration, with no sustained recovery from symptoms. ${ }^{14,15}$ PPMS is characterized by a gradual clinical decline with no periods of remission from the outset. ${ }^{16}$ There are several diagnostic tools used to identify the different MS types. ${ }^{1,2,17-19}$ MRI of the brain and spine is often performed; this shows areas of demyelination (lesions or plaques) in the absence or in the presence of gadolinium. ${ }^{20,21}$ Analysis of cerebrospinal fluid may provide evidence of chronic inflammation of the central nervous system by showing oligoclonal bands of immunoglobulin $\mathrm{G}$ (IgG). ${ }^{22}$ We use evoked potentials to study demyelination of the optic and sensory nerves. ${ }^{23}$ A clear demonstration of topographic correspondence between MS plaques and the cerebral venous system has been shown by $\mathrm{MRV}^{7,24}$ and postmortem studies. ${ }^{25}$

The new nosological vascular pattern, defined as chronic cerebrospinal venous insufficiency (CCSVI), is strongly associated with $\mathrm{MS} .{ }^{24}$ Although both pathogenetic hypothesis and mode of treatment are highly controversial issues, a marked symptomatic improvement has been observed in several series of patients with MS who had undergone endovascular internal jugular vein (IJV) angioplasty. CCSVI is characterized by multiple stenosis/obstructions affecting the principal extra-cranial outflow pathways of the cerebrospinal venous system, the IJVs, and the azygos vein (AZY), distributed in four main hemodynamic patterns. ${ }^{23}$ Furthermore, CCSVI determines significant changes in the cerebral venous hemodynamic, with a very high incidence of reflux in both intra-cranial and extra-cranial venous segments, and loss of the postural regulation of cerebral venous outflow. ${ }^{24,25}$ Recently, Zamboni Consensus $2011^{26}$ suggested five echo color Doppler (ECD) venous criteria that characterize this syndrome as the following: 1) reflux constantly present in an outflow pathway; 2) reflux propagated upward to the deep cerebral veins (DCVs), including internal cerebral vein, basal vein, and Galen vein; 3) evidence of IJV stenosis; 4) flow not Doppler-detectable in the IJVs and vertebral veins (VVs); and 5) negative difference in cross-sectional area (CSA) of the IJV, assessed in supine $\left(0^{\circ}\right)$ and standing $\left(90^{\circ}\right)$ posture, seen as change in the cross-sectional area $(\triangle \mathrm{CSA})$ of the IJV. ${ }^{25}$ The presence of any two of the five criteria is sufficient for the diagnosis of CCSVI.

\section{Methods}

The aim of our study was to assess the size of the third ventricle in a sample of patients with multiple sclerosis (MS) affected by chronic cerebrospinal venous insufficiency (CCSVI) versus a healthy control group.

We enrolled 33 patients affected by MS (three in the primary progressive clinical course, 23 in the relapsingremitting clinical course, and seven in the secondaryprogressive clinical course). All patients had been affected by CCSVI and were tested using an Esaote Mylab 25 echo color Doppler (ECD) imaging unit (Esaote SpA, Genoa, Italy). The group of 33 affected by both MS and CCSVI (MS-CCSVI) was composed of 19 females and 14 males with a mean age of $40 \pm 10$ years, from a minimum age of 20 to a maximum age of 66 years, with a median of 40 years and a mode of 32 years. We compared the 33 MS-CCSVI patients with 33 healthy control subjects of similar sex and age. The 33 healthy control subject group had a mean age of 41.9 years and was composed of $36 \%$ males and $64 \%$ females. In the MS-CCSVI group, the MS clinical severity was expressed by expanded disability status scale (EDSS) score: light (19 patients, scoring 1, 2, or 3); medium (ten patients with a score of 4, 5, or 6), and severe (four patients with a score of 7,8 , or 9 ). The average duration of the MS was $10 \pm 7$ years (from a minimum of 1 to a maximum of 26 years, with a median of 10 years and a mode of 1 year). Written informed consent was obtained from all subjects.

\section{ECD assessment of cerebral venous hemodynamics}

Our patients underwent a non-invasive study of cerebral venous return. A combined trans-cranial and extra-cranial ECD equipped with 2.5 and 7.5-10 Mhz probes provided valid measures of venous hemodynamic (VH) parameters, enabling an assessment of CCSVI cerebral venous drainage. ECD medical reports have been reported on a morphological hemodynamic map of the National Epidemiological Observatory on CCSVI for the extraction of statistical data (Figure 1). The subjects were investigated in both supine and standing positions $\left(0^{\circ}\right.$ and $90^{\circ}$, respectively) in consideration 
Venous echo color Doppler

CARDIOVASCOLARI RESPIRATORIE

E MORFOLOGICHE

SAPIENZA

UniversITA DI ROMA

CCSVI "SAPIENZA" center Viale del policlinico, 155-00161-Roma Tel 0649979001

e-mail: s.mandolesi@email.it

Supine: red color

Upright: green color

\begin{tabular}{|c|c|}
\hline \multicolumn{2}{|c|}{ CSA Sx } \\
\hline 120,00 & 150,00 \\
\hline 45,00 & 56,00 \\
\hline
\end{tabular}



\begin{tabular}{|c|c|c|}
\hline $\begin{array}{l}\text { Zamboni criteria } \\
\square \text { Criterion } 1 \\
\square \text { Criterion } 2 \\
\square \text { Criterion } 3 \\
\square \text { Criterion } 4 \\
\square \text { Criterion } 5\end{array}$ & & $\begin{array}{l}\text { CCSVI type } \\
\square \text { Type } 1 \\
\square \text { Type } 2 \\
\square \text { Type } 3\end{array}$ \\
\hline $\begin{array}{l}\text { ID patient: } 756 \quad \text { Sex: } F \\
\text { Age: } 33 \\
\text { Clinical type: SP } \\
\text { First symptom: optical neuryte left eye } \\
\text { Duration: } 13 \text { years }\end{array}$ & EDSS: 4 & $\begin{array}{l}\text { Score } \\
\text { CCSVI: } 1 \quad \text { CCSVI is positive if } \geq 2 \text { criteria } \\
\text { VHISS: } 2 \\
\text { MEM: } 15 \\
\text { Date: } 01 / 27 / 2013 \\
\text { Sonographer: Prof Sandro Mandolesi }\end{array}$ \\
\hline
\end{tabular}

Figure I Morphological hemodynamic map (MEM) scheme representing pattern of ECD venous cerebrospinal drainage, CCSVI type, hemodynamic severity score, and patient data.

Abbreviations: CCSVI, chronic cerebrospinal venous insufficiency; CSA, cross-sectional area; ECD, echo color Doppler; SP, secondary-progressive; EDSS, expanded disability status scale; F, female; VHISS, venous hemodynamic insufficiency severity score; Dx, right; Sx, left.

of the postural effect on the main route of cerebral outflow.

We focused on the detection of five anomalous VH patterns (described above) affecting cerebral venous draining flow according to the Zamboni Criteria of 2011 Consensus $^{22-26}$ as stated below.

Diencephalic floor: a depth of the initial 140-160 mm is essential, in order to arrive at the optimum contralateral sonorization and have a complete picture of brain structures.
It is recommended that a dynamic range between 45-50 dB be used (Figure 2). The best sonorization of brain parenchyma by $\mathrm{B}$ mode examination with the least disturbance to artifacts we have is by transtemporal access, contralateral to the target side.

The subjects were investigated in supine position. The landmark is the image double track of the third ventricle with hyperechoic edges that is normally at about $50-60 \mathrm{~mm}$ 




Figure 2 Representative third ventricle with typical image track.

in the diencephalic plan (Figure 3). The third ventricle will be identified frontal to horns of the lateral ventricles and anterior to the pineal gland. This gland is the landmark for the correct sonorization of the vein of Galen which normally has a flow away from the probe.

The determination of the width of the third ventricle is easily traceable above the double track of ependyma. From the data available in the literature, it is considered the normal size of the third ventricledoes not exceed $4 \mathrm{~mm}^{27}$

\section{Statistical analysis}

All data were analyzed by SPSS (Statistical Package for the Social Sciences, version 19, IBM Corporation, Chicago, Illinois, USA) to enable a stratified data description for numeric parametric variables. Statistical significance between and within groups was calculated on continuous variables by analysis of variance (ANOVA) to test the equality of means. The chi-square $\left(\chi^{2}\right)$ Yates-corrected test was used for non-continuous variables by Statcalc and Analysis programs available through Epi Info ${ }^{\mathrm{TM}}$ (US Centers for

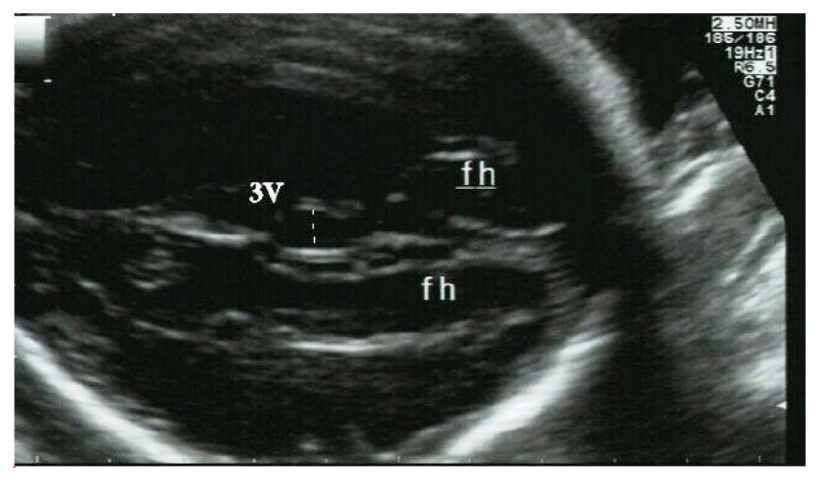

Figure 3 Representative third ventricle.

Note: The white dotted line is the diameter of the third ventricle.

Abbreviations: 3V, third ventricle; fh, frontal horn.
Disease Control, Atlanta, GA, USA). A $P$-value of $<0.05$ was considered significant, and $95 \%$ confidence intervals were also calculated.

\section{Results}

Of the 33 patients with MS enrolled in the study, 29 patients $(88 \%)$ showed an increase in the size of the third ventricle (positive group), and four patients (12\%) had normal size within $4 \mathrm{~mm}$ (negative group). All 33 healthy control group subjects showed normal third ventricle size.

The mean size of the diameter of the third ventricle was $6.2 \pm 1.7 \mathrm{~mm}$, from a minimum of 2.5 to a maximum of $9.2 \mathrm{~mm}$, with a median of 6.3 and a mode of $6.0 \mathrm{~mm}$ (Table 1). In the healthy subjects control group, the mean size of the diameter of the third ventricle was $3.4 \mathrm{~mm}$.

\section{Patients with less than II years of MS duration}

Eighteen subjects (eight females and ten males) were enrolled in this study group. Sixteen of the 18 subjects were affected by CCSVI. The average age was 36 years \pm 9 years (from a minimum of 20 years to a maximum of 53 years, with a median of 34 years and a mode of 29 years). All subjects were suffering from MS (one subject was diagnosed with PPMS, 16 subjects were diagnosed with RRMS, and one subject was diagnosed with SPMS). Severity of the disease was expressed by EDSS scores of varying severity: low (13 patients scoring 1,2 , or 3 ); medium (four patients scoring 4,5 , or 6 ), and high (one patient with a score of 7,8 , or 9 ). The mean duration of the MS was 5 years \pm 3 years (from a minimum of 1 year to a maximum of 10 years, with a median of 5 years and a mode of 1 year). In this stratification, the average size of the diameter of the third ventricle was 6.2 $\mathrm{mm} \pm 1.7 \mathrm{~mm}$ (from a minimum of $2.5 \mathrm{~mm}$ to a maximum of $8.6 \mathrm{~mm}$, with a median of $6.4 \mathrm{~mm}$ and a mode of $6.1 \mathrm{~mm}$ ). Table 2 summarizes the findings in this group.

\section{Patients with more than 10 years of MS duration}

Fifteen subjects (eleven females and four males) were studied in this stratification. Fourteen of the 15 subjects were affected with CCSVI. The mean age was 45 years \pm 9 years, from a minimum of 32 years to a maximum of 66 years, with a median of 45 years and a mode of 36 years. All subjects were suffering from MS (two MSPP subjects, six MSRR subjects, and seven MMSP subjects). The severity of the disease was expressed by 
Table I Comparisons of average diameters of third ventricles within EDSS score groupings

\begin{tabular}{lllllll}
\hline $\begin{array}{l}\text { EDSS } \\
\text { score }\end{array}$ & $\begin{array}{l}\text { Patients } \\
(\mathbf{n})\end{array}$ & $\begin{array}{l}\text { Third ventricle diameter } \\
\text { (mean value } \pm \text { standard } \\
\text { deviation) }\end{array}$ & $\begin{array}{l}\text { Diameter } \\
\text { (minimum) }\end{array}$ & $\begin{array}{l}\text { Diameter } \\
\text { (maximum) }\end{array}$ & $\begin{array}{l}\text { Diameter } \\
\text { (median) }\end{array}$ & $\begin{array}{l}\text { Diameter } \\
\text { (mode) }\end{array}$ \\
\hline 1, 2, or 3 & 19 & $5.9 \pm 1.7$ & 2.5 & 8.9 & 6.1 & 6.0 \\
4,5 , or 6 & 10 & $6.3 \pm 2.0$ & 2.7 & 9.2 & 6.3 & 6.7 \\
7 , 8, or 9 & 4 & $7.1 \pm 0.8$ & 6.4 & 8.3 & 6.9 & 6.4 \\
\hline
\end{tabular}

Note: Diameter values are expressed in millimeters.

Abbreviation: EDSS, expanded disability status scale.

EDSS scores of varying severity: low (six patients scoring 1,2, or 3), medium ( six patients with scores of 4,5 , or 6 ), and high (three patients with scores of 7,8, or 9). The average duration of MS was 17 years \pm 5 years (from a minimum of 11 years to a maximum of 26 years, a median of 19 years, and a mode of 19 years). In this group, the average diameter of the third ventricle was $6.1 \mathrm{~mm} \pm 1.8 \mathrm{~mm}$ (from a minimum of $2.7 \mathrm{~mm}$ to a maximum of $9.2 \mathrm{~mm}$, with a median of $6.0 \mathrm{~mm}$ and a mode of $2.7 \mathrm{~mm}$ ). Table 3 compares average diameters of third ventricles of patients with more than 10 years of MS duration, within the groupings of their EDSS scores.

\section{Discussion}

When compared with MRI, the most relevant limitation of transcranial sonography (TCS) to assess brain atrophy is its poor ability to examine cortical structures. Other limitations of TCS (such as the ultrasound penetration of the temporal skull) are less relevant, because most patients with MS belong to an age group with usually good penetration conditions. We believe that the increase in size of the third ventricle could be linked to the pathophysiology of MS. Either the presence of anomalies in the venous valves, in the internal jugular veins, or their flow reflux, can lead to a stasis of blood drainage and effects on cerebrospinal fluid.
We hypothesize that the blood drainage stasis leads to an increase of cerebrospinal fluid in the brain, with evident dilation of the third ventricle. The mean values of diameters in patients with less than 11 years of MS duration stratified by EDSS score are interesting. In fact, a previous study showed a direct correlation between disease duration and EDSS scores. ${ }^{28}$ Our findings also illustrate (sample permitting) direct proportionality between the mean diameter of the third ventricle and EDSS score in patients with disease duration of less than 10 years. Our results are in agreement with Walter et $\mathrm{al}^{31}$ for an MS patient cohort similar to ours, and with Berg et al, ${ }^{29}$ who investigated a cohort of patients with severe MS of longer disease duration. Our findings are also in agreement with Müller et al, ${ }^{30}$ who found that the width of the third ventricle in 54 patients with MS was significantly related to EDSS (Spearman $r=0.446, P<0.005$ ) and to MS duration ( $r=0.319, P<0.005)$ but not to age. Our findings are also in agreement with a related study of the general population. ${ }^{23}$ We believe, in light of the data collected, that further study of the third ventricle in patients with CCSVI is needed. Our results show that the increase in the third ventricle diameter could represent a criterion of positivity of neurologic diseases in patients with CCSVI.

Table 2 Patients with MS duration of less than II years: comparisons of average diameters of third ventricles within groupings of EDSS scores $(P=0.026 \mathrm{I})$

\begin{tabular}{lllllll}
\hline $\begin{array}{l}\text { EDSS } \\
\text { score }\end{array}$ & $\begin{array}{l}\text { Patients } \\
\text { (n) }\end{array}$ & $\begin{array}{l}\text { Third ventricle diameter } \\
\text { (mean value } \pm \text { standard } \\
\text { deviation) }\end{array}$ & $\begin{array}{l}\text { Diameter } \\
\text { (minimum) }\end{array}$ & $\begin{array}{l}\text { Diameter } \\
\text { (maximum) }\end{array}$ & $\begin{array}{l}\text { Diameter } \\
\text { (median) }\end{array}$ & $\begin{array}{l}\text { Diameter } \\
\text { (mode) }\end{array}$ \\
\hline I, 2, or 3 & 13 & $5.6 \pm 1.7$ & 2.5 & 7.6 & 6.1 & 6.1 \\
4 , 5, or 6 & 4 & $7.6 \pm 0.9$ & 6.5 & 8.9 & 7.7 & 6.5 \\
7 , 8, or 9 & 1 & $8.3 \pm 0.0$ & 8.3 & 8.3 & 8.3 & 8.3 \\
\hline
\end{tabular}

Note: Diameter values are expressed in millimeters.

Abbreviation: EDSS, expanded disability status scale; MS, multiple sclerosis. 
Table 3 Patients with MS duration of more than 10 years: comparisons of average diameters of third ventricles within groupings of EDSS scores

\begin{tabular}{lllllll}
\hline $\begin{array}{l}\text { EDSS } \\
\text { score }\end{array}$ & $\begin{array}{l}\text { Patients } \\
(\mathbf{n})\end{array}$ & $\begin{array}{l}\text { Third ventricle diameter } \\
\text { (mean value } \pm \text { standard } \\
\text { deviation) }\end{array}$ & $\begin{array}{l}\text { Diameter } \\
\text { (minimum) }\end{array}$ & $\begin{array}{l}\text { Diameter } \\
\text { (maximum) }\end{array}$ & $\begin{array}{l}\text { Diameter } \\
\text { (median) }\end{array}$ & $\begin{array}{l}\text { Diameter } \\
\text { (mode) }\end{array}$ \\
\hline 1, 2, or 3 & 6 & $6.4 \pm 2.0$ & 3.6 & 8.9 & 5.8 & 3.6 \\
4,5 , or 6 & 6 & $5.5 \pm 2.2$ & 2.7 & 9.2 & 5.2 & 6.7 \\
7, 8, or 9 & 3 & $6.7 \pm 0.3$ & 6.4 & 7.1 & 6.7 & 6.4 \\
\hline
\end{tabular}

Note: Diameter values are expressed in millimeters.

Abbreviation: EDSS, expanded disability status scale; MS, multiple sclerosis.

\section{Disclosure}

The authors report no conflicts of interest in this work.

\section{References}

1. Compston A, Coles A. Multiple sclerosis. Lancet. 2002;359(9313): 1221-1231.

2. Barnett MH, Sutton I. The pathology of multiple sclerosis: a paradigm shift. Curr Opin Neurol. 2006;19(3):242-247.

3. Frohman EM, Racke MK, Raine CS. Multiple sclerosis - the plaque and its pathogenesis. N Engl J Med. 2006;354(9):942-955.

4. Charcot JM. Histologie de la sclérose en plaques [Histology of multiple sclerosis]. Gazette des Hopitaux, Paris. 1868;41:554-555. French.

5. Kermode AG, Thompson AJ, Tofts P, et al. Breakdown of the blood-brain barrier precedes symptoms and other MRI signs of new lesions in multiple sclerosis. Pathogenetic and clinical implications. Brain. 1990;113(Pt5):1477-1489.

6. Kidd D, Barkhof F, McConnell R, Algra PR, Allen IV, Revesz T. Cortical lesions in multiple sclerosis. Brain. 1999;122(Pt1):17-26.

7. Tan IL, van Schijndel RA, Pouwels PJ, et al. MR venography of multiple sclerosis. AJNR Am J Neuroradiol. 2000;21(6):1039-1042.

8. Fog T. On the vessel-plaque relationships in the brain in multiple sclerosis. Acta Neurol Scand Suppl. 1964;40(10):9-15.

9. Fog T. The topography of plaques in multiple sclerosis with special reference to cerebral plaques. Acta Neurol Scand Suppl. 1965;15:1-161.

10. Sayre LM, Moreira PI, Smith MA, Perry G. Metal ions and oxidative protein modification in neurological disease. Ann Ist Super Sanita. 2005;41(2):143-164.

11. Haacke EM, Cheng NY, House MJ, et al. Imaging iron stores in the brain using magnetic resonance imaging. Mag Reson Imaging. 2005;23(1):1-25.

12. LeVine SM, Chakrabarty A. The role of iron in the pathogenesis of experimental allergic encephalomyelitis and multiple sclerosis. Ann NY Acad Sci. 2004;1012:252-266.

13. McDonald WI, Compston A, Edan G, et al. Recommended diagnostic criteria for multiple sclerosis: guidelines from the International Panel on the diagnosis of multiple sclerosis. Ann Neurol. 2001;50(1):121-127.

14. Polman CH, Reingold SC, Edan G, et al. Diagnostic criteria for multiple sclerosis: 2005 revisions to the "McDonald Criteria". Ann Neurol. 2005;58(6):840-846.

15. Rashid W, Miller DH. Recent advances in neuroimaging of multiple sclerosis. Semin Neurol. 2008;28(1):46-55.

16. Ge Y, Zohrabian VM, Grossman RI. Seven-Tesla magnetic resonance imaging: new vision of microvascular abnormalities in multiple sclerosis. Arch Neurol. 2008;65(6):812-816.

17. Link H, Huang YM. Oligoclonal bands in multiple sclerosis cerebrospinal fluid: an update on methodology and clinical usefulness. J Neuroimmunol. 2006;180(1-2):17-28.

18. Hojnacki D, Zamboni P, Lopez-Soriano A, et al. Use of neck magnetic resonance venography, Doppler sonography and selective venography for diagnosis of chronic cerebrospinal venous insufficiency: a pilot study in multiple sclerosis patients and healthy controls. Int Angiol. 2010;29(2):127-139.
19. Geurts JJ, Bö L, Pouwels PJ, Castelijns JA, Polman CH, Barkhof F. Cortical lesions in multiple sclerosis: combined postmortem MR imaging and histopathology. AJNR Am J Neuroradiol. 2005;26(3): 572-577.

20. Zamboni P, Galeotti R, Menegatti E, et al. Chronic cerebrospinal venous insufficiency in patients with multiple sclerosis. J Neurol Neurosurg Psychiatry. 2009;80(4):392-399.

21. Menegatti E, Zamboni P. Doppler haemodynamics of cerebral venous return. Curr Neurovasc Res. 2008;5(4) 4;260-265.

22. Zamboni P, Menegatti E, Galeotti R, et al. The value of cerebral Doppler venous hemodynamics in the assessment of multiple sclerosis. J Neurol Sci. 2009;282(1-2):21-27.

23. Zamboni P, Menegatti, E, Bartolomei, et al. Intracranial venous haemodynamics in multiple sclerosis. Curr Neurovasc Res. 2007;4(4): $252-258$.

24. Franceschi C. The unsolved puzzle of multiple sclerosis and venous function. J Neurol Neurosurg Psychiatry. 2009;80(4):358.

25. Gorucu Y, Albayram S, Balci B. Cerebrospinal fluid flow dynamics in patients with multiple sclerosis: a phase contrast magnetic resonance study. Funct Neurol. 2011;26(4):215-222.

26. Zamboni P, Morovic S, Menegatti E, Viselner G, Nicolaides AN. Screening for chronic cerebrospinal venous insufficiency (CCSVI) using ultrasound--recommendations for a protocol. Int Angiol. 2011;30(6):571-597.

27. Hernández NL, Escrivá AG, Jordà JM. Study of the diameter of the third ventricle with transcranial sonography. Neurologia. 2007;22(8): 507-510.

28. Mandolesi S, Manconi E, Niglio T, et al. Incidence of anatomical compression of the internal jugular veins with full block of their flow in patients with chronic cerebro-spinal venous insufficiency and multiple sclerosis; Allegra C, Antignani PL (editors). Proceedings of the 21st EUROCHAP - IUA European Chapter Congress of the International Union of Angiology, Rome, Italy, September 28 - October 1, 2013. Turin, Italy: Minerva Medica; 2013: 12-17. Available from http:// filesformailing.minervamedica.it/volumi/EUROCHAP.pdf. Accessed August 11, 2014.

29. Berg D, Mäurer M, Warmuth-Metz M, Rieckmann P, Becker G. The correlation between ventricular diameter measured by transcranial sonography and clinical disability and cognitive dysfunction in patients with multiple sclerosis. Arch Neurol. 2000;57(9):1289-1292.

30. Müller M, Esser R, Kötter K, et al. Third ventricular enlargement in early stages of multiple sclerosis is a predictor of motor and neuropsychological deficits: a cross-sectional study. BMJ Open. 2013;3(9):e003582. doi: 10.1136/bmjopen-2013-003582.

31. Walter U, Wagner S, Horowski S, Benecke R, Zettl UK. Transcranial brain sonography findings predict disease progression in multiple sclerosis. Neurology. 2009;73(13):1010-1017.

32. Müller M, Esser R, Kötter K, Voss J, Müller A, Stellmes P. Width of 3. Ventricle: reference values and clinical relevance in a cohort of patients with relapsing remitting multiple sclerosis. Open Neurol J. 2013;7:11-16. 
Journal of Vascular Diagnostics

\section{Publish your work in this journal}

Journal of Vascular Diagnostics is an international, peer-reviewed journal of diagnostics, focusing on non invasive vascular investigation methods involved in the evaluation of vascular diseases. The journal is committed to the rapid publication in the fields of vascular diseases. Original research, review, case reports, expert opinion and commentaries

Submit your manuscript here: http://www.dovepress.com/journal-of-vascular-diagnostics-journal

are all considered for publication. The manuscript management system is completely online and includes a very quick and fair peer-review system, which is all easy to use. Visit http://www.dovepress.com/testimonials.php to read real quotes from published authors. 